\title{
A PAISAGEM AGRÁRIA NA OBRA DE LEO WAIBEL
}

\author{
VIRGÍNIA ELISABETA ETGES* \\ Universidade de Santa Cruz do Sul
}

Segundo Figueiró, o alvorecer do século XIX, na Europa, encontra a idéia de paisagem dividida em duas grandes correntes. De um lado a França e a maior parte dos países europeus, onde a separação entre arte e ciência já estava nitidamente instalada, levando a duas idéias básicas de paisagem: uma relativa à idéia de paisagem-natureza, "esquartejada" pela ciência analítica e representando um instrumento do modo capitalista de produção; outra, ligada à emergência de uma sensibilidade artística, percebendo a paisagem somente a partir do seu simbolismo estético. Tal dicotomia conceitual (sentidos científico e estético) relegou o termo paisagem a um uso cada vez mais infreqüente naqueles países, inspirados na tradição científica francesa. De outro lado, uma Alemanha impulsionada pelos ideais do romantismo, onde esta separação não aconteceu. A idéia de naturphilosophie formava uma terceira via ${ }^{1}$ na idéia de paisagem: uma visão holística, integradora, panteísta, que não reconhece divisões entre arte, ciência e religião ou público e privado.

Tal concepção representava muito mais do que um simples resgate da idéia de paisagem enquanto totalidade. Por intermédio desta corrente filosófica se dava a contestação de todo um modo de fazer ciência, erigido até então pelos teóricos iluministas.

\footnotetext{
* Doutora em Geografia Humana pela Universidade de São Paulo - USP. Professora de Geografia e Coordenadora do Programa de Pós-Graduação em Desenvolvimento Regional, nível de Mestrado, na Universidade de Santa Cruz do Sul-RS - UNISC.

${ }^{1}$ Nem arte nem ciência mas, antes disso, as duas coisas juntas.
} 
A obstinação dos românticos em resgatar a unidade perdida entre homem e natureza vinha ao encontro da necessidade de estruturação de uma perspectiva mais global na análise da paisagem, fato esse que contribuiu para que se desse na Alemanha a incorporação da noção de paisagem (enquanto totalidade dos elementos observáveis no espaço) na ciência de maneira geral e, mais especificamente, na Geografia.

Estas idéias tiveram influência marcante no pensamento e na obra de Waibel.

Para que se compreenda a importância da contribuição de Leo Waibel à Geografia na Alemanha, entretanto, é fundamental compreender o contexto sócio-político, econômico e cultural da realidade alemã da época em que o mesmo realizou suas pesquisas naquele país (período de 1910 a 1938), que influenciou sua atuação enquanto cidadão, professor e pesquisador.

Não há dúvida de que Leo Waibel foi um dos geógrafos mais importantes na Alemanha no período entre-guerras. Isto deve-se, por um lado, a sua significativa contribuição teórica, onde partiu de análises do mundo das plantas e dos animais, resultantes de suas pesquisas na África no início de sua carreira de pesquisador para, no final da década de vinte, realizar suas primeiras pesquisas em continente americano onde o homem, enquanto forjador da paisagem cultural, passa a ser o objeto central de sua atenção.

De pesquisador engajado no projeto imperialista alemão (décadas de 10 e 20) Waibel passa a incorporar, a partir de novas experiências, tanto na África (trabalho sobre os Treckburen), na Alemanha (ascensão do nazismo), como na América (sul do México - Serra Madre de Chiapas), novos elementos a suas observações enquanto produtor de conhecimento científico, que vão caracterizá-lo, a partir de então, como um dos expoentes da Geografia Econômica alemã.

Dois conceitos destacam-se na elaboração teórica do autor durante este período: o de "Wirtschaftsformation" (Formação Econômica) e o de "Kulturlandschaft" (Paisagem Cultural).

Analogamente a uma formação vegetal, afirma Waibel, uma Paisagem Econômica contínua pode ser denominada de Formação Econômica. A agricultura emprega para estas unidades, sejam extensas ou reduzidas, geralmente a denominação de "zonas" e fala assim de uma zona de cultura de hortaliças, uma triticultora, uma zona de lacticínios, etc.

Já a Paisagem Cultural, dentro da Geografia Agrária, o autor entende como resultante do uso do solo, ou seja, do tipo de cultivos, técnicas utilizadas, estradas e instalações, determinado pela Formação Econômica.

Estes conceitos foram muito debatidos pelos geógrafos alemães ao longo do século $\mathrm{XX}$, o que fez com que a obra de Leo Waibel se tornasse marcante, não só na Alemanha, mas em vários países onde a questão agrária esteve na ordem do dia no transcorrer daquele século.

Mas, quem foram os autores que inspiraram Waibel, que influenciaram sua obra? Sem dúvida nenhuma Carl Ritter e Alfred Hettner tiveram destaque neste cenário. 
Resgatar o processo de produção do conhecimento geográfico, mais especificamente a produção dos geógrafos alemães tidos como os "fundadores da Geografia moderna", é indispensável para desenvolver o tema em questão. ${ }^{2}$

A Geografia, como saber específico no campo das ciências, já passou por várias crises. Discussões metodológicas e críticas a princípios são, segundo Kuhn, expressões de uma crise da ciência em questão: elas assinalam o despedaçar do velho e a criação do novo. Crítica e crise são assim dois aspectos de uma mesma questão: o crítico é indicador de uma crise e ele busca a solução da crise ao fazer a crítica (Kuhn apud SCHULTZ 1980:41).

Neste sentido, uma das discussões mais marcantes realizada pelos geógrafos relaciona-se à origem e à sistematização do conhecimento geográfico.

Os geógrafos apontam, de forma estereotipada, Alexander Von Humboldt e Carl Ritter como fundadores da Geografia moderna, quando, na realidade, o valor atribuído à sua contribuição parece estar em relação direta aos interesses em jogo por parte dos defensores desta colocação, afirmou Schultz, em sua obra A Geografia Alemã de 1800 a 1970 - contribuição para a história da sua metodologia, publicada em Berlim em 1980.

Segundo Schultz, para o cientista natural e geólogo Ferdinand Von Richthofen, Humboldt estava em primeiro lugar: a ele estava reservado criar a Geografia (Erdkunde) como ciência natural, depois da contribuição de Varenius ter sido praticamente desconsiderada. No entanto, muitas das realizações de Humboldt cairam novamente no esquecimento, na medida em que não ele, senão Ritter passou a ser visto como representante acadêmico da disciplina.

Richthofen, em 1883, apontou como atributo da Geografia (Länderkunde) de Ritter a caracterísitca da compilação. E afirma que quanto mais o lado material da Geografia, atribuído a Humboldt, se afirma nos dias de hoje, tanto mais claro se torna a contribuição de Ritter, que despertou a concepção idealista da Geografia (Ideale Anschauungsweise). Da junção das duas resulta a Geografia de hoje.

Mas em uma de suas palestras, em 1903, Richthofen reportou-se novamente quase que exclusivamente à linha tradicional de Varenius, Humboldt e Peschel, apontando a Antropogeografia, resultante do aperfeiçoamento das idéias de Ritter, juntamente com a Biogeografia, como áreas intermediárias (Zwischenfächer) cuja atividade pode se relacionar tanto à Geografia Física como às ciências biológicas e humanas (Richthofen, apud SCHULTZ, 1980:41).

Da mesma forma Tiessen, em 1908, manifestou sua crítica a Ritter afirmando que a colocação de Richthofen sobre a importante contribuição de Ritter à Geografia mere-

\footnotetext{
${ }^{2}$ Este tema também foi abordado pela autora em Etges, 2000(a) e 2000(b).
} 
ce destaque, mas enfatizou que não é demais dizer que, apesar desta contribuição, Ritter retirou a base sobre a qual a Geografia, a partir de Varenius e seguindo com Humboldt, poderia ter se desenvolvido. Mas como o desenvolvimento da Geografia não podia mais ser detido e, em vista da pequena contribuição dos geógrafos, os geólogos e metereólogos tomaram a sí o desenvolvimento da Geografia Física (Tressen, apud SCHULTZ, 1980:42).

Outros geógrafos da mesma época, também citados por Schultz, no entanto, manifestaram opiniões bem diferentes daquelas anteriormente expostas. Hassinger, por exemplo, afirmou, em 1919, que Ritter é o fundador da Geografia Comparada (Vergleichende Erdkunde), que se sobrepôs ao estado de inércia em que a Geografia se encontrava, dando à mesma unidade e coerência, e introduziu nela a nascente concepção de desenvolvimento. Geistbeck, por sua vez, em 1918, afirmou que "nós estamos acostumados a relacionar a criação de uma nova Geografia ao nome de Ritter. Na realidade ele somente reconheceu o verdadeiro caráter da Geografia (Erdkunde) quando a definiu como a ciência dos espaços da superfície terrestre e os elementos ali presentes." Já Scherer em 1908, afirmou que o verdadeiro arquiteto da ciência geográfica foi Carl Ritter, na medida em que ele lhe atribuiu um objetivo específico, apontando os meios e o caminho para a sua consecução, atribuindo à Geografia (Erdkunde), desta forma, uma posição livre e autônoma (SCHULTZ, 1980:43).

Hettner também falou dos dois grandes fundadores da moderna Geografia científica, Humboldt e Ritter, mas afirmou que "a forma da ciência, que Humboldt apontava, não é a Geografia no sentido que se lhe atribui hoje. A contribuição de Ritter foi muito maior neste sentido. Ele é o criador da sua metodologia (aqui entendida como essência (Wesen), conceito (Begriff), objetivo (Ziel) e objeto (Gegenstand) da Geografia)". E complementa dizendo que "Carl Ritter promoveu a Geografia à condição de ciência, especialmente a Geografia Regional (Länderkunde), que até então não passava de uma serviçal a serviço da prática da vida cotidiana" (Hettner, apud SCHULTZ, 1980:42).

Já para Penck, a influência de Humboldt extrapolou em muito as fronteiras da Geografia. Ele foi cosmógrafo e não geógrafo, disse o autor em 1928. A ele muito a Geografia tem a agradecer, mas não a sua estruturação sistemática. Esta aconteceu no período clássico, com Ritter. Mesmo que ele tenha conservado o nome Erdkunde, ele se limitou, na sua Geografia Comparada (vergleichenden Geographie) à superfície terrestre. Com isto ele estabeleceu a consistente base para a concepção atual de Geografia como ciência da superfície terrestre (Penck, apud SCHULTZ, 1980:43).

Schrepfer, por sua vez, em sua obra de 1934, também citado por Schultz, afirmou que o efeito de Ritter sobre a Geografia, não pode, nem de longe, ser comparado com o de Humboldt. Ritter, enquanto criador da Antropogeografia, deu primazia à Geografia Regional (Länderkunde) sobre a Geografia Geral, entendendo os espaços dos países (Länderräume) como "grandes indivíduos", limitando a abrangência da Geografia de ciência da Terra aos fenômenos concretos da superfície terrestre, criando 
uma Geografia muito mais específica e autônoma do que a de Humboldt (Schrepfer, apud SCHULTZ, 1980:43).

Passarge, em 1931, afirmou que Ritter projetou-se para muito além do seu tempo, quando definiu a Geografia (Erdkunde) como a ciência dos fenômenos concretos da superfície terrestre, colocando como objeto da Geografia o que nós hoje denominamos paisagem. Esta afirmação, no entanto, contradiz outra, de 1924, onde o mesmo autor afirmou que a teoria dos fenômenos concretos da superfície terrestre de Ritter cobre-se com o conceito de Geografia Regional na medida em que considera todos os fenômenos. Em nenhum momento trata-se nela de Geografia da Paisagem Comparada (Vergleichender Landschaftskunde) (Passarge, apud SCHULTZ 1980:43).

Plewe também deu a sua contribuição nesta discussão, quando afirmou, em 1952, que a essência das palavras de Kant é válida até hoje, dizendo que Hettner se refere a elas como a descrição esclarecedora da essência dos países (Länder) e das paisagens (Landschaften), ressaltando que Kant teria formulado seu programa com exatidão, não tendo podido, porém, executá-lo. Na concepção de Plewe não foi Ritter e sim Humboldt quem, através do trabalho sobre a "Nova Espanha", atendeu às formulações de Kant na prática. A respeito de Ritter dizia-se, segundo Plewe, que teria apreendido com Humboldt a essência das coisas. Desta forma, contariam Kant e Humboldt como fundadores da moderna Geografia. Mesmo que para Plewe, Ritter tenha sido considerado, na essência, o "criador do chão para a Geografia como ciência", isto parece estar fundamentado unicamente no fato dele, ao contrário de Kant e Humboldt, não ter praticado a Geografia como atividade complementar, e sim de ter se dedicado à ela com exclusividade, tendo se tornado um geógrafo (Plewe, apud SCHULTZ, 1980:44).

A partir destas colocações torna-se bem evidente a polêmica existente entre os próprios geógrafos alemães a respeito da importância da contribuição dos assim chamados "pais da Geografia moderna" ao desenvolvimento do pensamento geográfico.

Entretanto, para que se possa avançar nesta discussão é necessário retroceder no tempo, para além de Humboldt e Ritter. Segundo Schmithüsen, praticamente todos os importantes geógrafos que se ocuparam com a História da Geografia, de Humboldt até Richthoffen e Ratzel, apontaram Varenius como precursor mais significativo, quando não fundador da Geografia moderna, e reconheceram a genialidade de sua obra. Bernard Varenius viveu somente 28 ou 29 anos, não se sabe ao certo se nasceu em 1621 ou 1622. Nunca realizou pesquisas de campo, nem viajou. Todas as fontes que utilizava em seus trabalhos já eram conhecidas. Na realidade, a importância da sua contribuição reside no fato dele ter ordenado as informações, às quais tinha acesso, num sistema. A publicação e a disseminação das suas idéias deve-se a Newton (1643-1727), o qual, por muito tempo fez da Geographia Generalis a obra modelo na Inglaterra. Newton mesmo também deu aulas de Geografia onde revidava afirmações da Geographia Generalis, a qual ele também traduziu para o inglês. Portanto, a obra de Varenius foi fundamental para o desenvolvimento da Geografia, tanto na Inglaterra, como mais tarde na Alemanha, inclusive para Kant (1724-1804), que ter- 
se-ia apoiado em sua obra. Varenius foi o primeiro geógrafo da época moderna que, de forma consciente e objetiva, refletiu sobre a construção da Geografia.

Segundo Varenius, a ciência Geográfica deve estar fundamentada na exploração crítica de observações, na definição e descrição dos fatos e deve pesquisar e descrever as relações causais entre os fatos (SCHMITHÜSEN, 1970: 119-120).

Uma das partes mais importantes do livro Geographia Generalis é a introdução, onde o autor discutiu a teoria da Geografia, afirmando que a sua atribuição básica está em pesquisar a superfície terrestre e suas partes:

o objeto da Geografia, ou seja a matéria que deve ser esclarecida é, em primeiro lugar, a terra como um todo, acima de tudo a sua superfície e suas partes (Varenius apud SCHMITHÜSEN, 1980:120).

A Geographia Generalis era composta de três partes: a primeira era denominada Pars Absoluta, onde Varenius abordava a Terra como um todo e suas formas, abordando seu tamanho, os movimentos, distribuição de terras emersas e águas, montanhas e suas formas, florestas, desertos, mares, rios, circulação atmosférica, ventos, etc. O seu objetivo era classificar em tipologias todos os conhecimentos que se tinha até então sobre a Terra. A segunda parte chamava-se Pars Respectiva e tratava da diferenciação na superfície terrestre definida a partir da influência das camadas externas à Terra. A definição de zonas climáticas e sua influência sobre a vida humana era um dos temas principais. A terceira parte era denominada Pars Comparativa onde Varenius estudava a influência da localização na superfície terrestre, compreendida a partir da comparação. No entanto, na introdução da Geographia Generalis, Varenius introduziu a Geographia Specialis, colocada no mesmo nível de importância daquela, o que levava a crer que o autor tinha a intenção de aprofundá-la no mesmo nível da primeira. $\mathrm{O}$ trabalho realizado sobre o Japão era uma evidência neste sentido.

Na Geographia Specialis Varenius apresentou o mesmo esquema da Geographia Generalis, só que relacionado ao caráter individual de uma área, onde as três partes passaram a ser denominadas Afectiones. Assim, ele denominou a primeira parte, correspondente a Pars Absoluta na Geographia Generalis, de Afectiones Terrestres, onde abordava os condicionamentos telúricos de determinada área. Estes aspectos foram trabalhados no estudo sobre o Japão a partir de dez pontos, sistematicamente ordenados no sentido do "esquema regional" (länderkundliche Schema). Portanto, segundo Schmithüsen, a idéia da construção de uma Geografia Regional (Landeskunde) sistematicamente ordenada a partir de grupos de fatores específicos, já estava presente em Varenius, expressa em seu livro sobre o Japão e teoricamente explicitada na introdução da Geographia Generalis. Na segunda parte do texto, analogamente a Pars Respectiva da Geographia Generalis, foi feito o estudo das influências externas, denominada Afectiones Coelestes. E, na terceira parte, finalmente, o homem foi trazi- 
do, como determinante, para o primeiro plano, incluindo estudos etnográficos, históricos e sócio-geográficos, denominada Afectiones Humanae.

Portanto, a discussão sobre uma Geografia Geral e uma Geografia Regional, já estava presente em Varenius, quando ele afirmava que a Geographia Generalis não tinha só sentido por si mesma, mas que ela abordava os fenômenos de forma tipológica, o que era simultaneamente uma preparação para a Geographia Specialis, na qual os resultados da Geographia Generalis seriam aproveitados. Concluindo, Schmithüsen afirmou que as concepções teóricas de Varenius, incorporadas mais tarde por Humboldt e Ritter, eram mais importantes para a História da ciência geográfica, do que até então se imaginava (SCHMITHÜSEN, 1970: 122-127).

A partir destas colocações podemos averiguar que a origem do pensamento geográfico moderno remonta a "geógrafos" anteriores a Humboldt e Ritter.

Ritter mesmo escreveu em 1822, que

como disciplina histórica a Geografia até agora não passa de uma mistura sem regras internas; ela espera, sob o peso da escória, que a cobre, o sinal prateado do qual ela nascerá como ciência sólida (Ritter, apud SCHULTZ, 1980:44).

Na busca desta "regra interna" Ritter seguiu as trilhas do pensamento cosmológico (Kosmologischer Denkmotiv). O olhar cosmológico sobre toda a natureza torna-se o sinal prateado dos geógrafos: somente na conjugação de suas forças, na correlação de suas manifestações ela (a natureza) quer ser observada, afirmou Ritter.

A regra básica, que deve garantir a veracidade do todo, é a observação, continuou Ritter. O arranjo de todas as evidências recolhidas precisa, para ser metódico e para conduzir a um sistema natural, de um ponto de apoio, uma referência ideal (ideale Hintergrund). Só através dele os aspectos empíricos podem ser correlacionados e o diverso pode constituir-se em unidade.

A partir destas colocações, segundo Schultz, esperava-se que Ritter divulgasse sua referência ideal, sua teoria. Ao invés disto ele afirmou que a sua idéia básica (Grundidee) não poderia ser definida de saída, nem limitada em sua essência, senão que somente poderia adquirir forma através do desenrolar do processo, culminando com a conclusão. Como fundamentação neste sentido Ritter afirmou que a referência ideal não está para ele na veracidade de um conceito, e sim no conteúdo todo de todas as verdades existentes para ele, ou seja, no nível da fé (im Gebiete des Glaubens). Ela baseia-se numa contemplação interior, que se desenvolve a partir da sua vida em contato com a natureza e a humanidade (Ritter, apud SCHULTZ, 1980:45-46).

Assim, duas concepções básicas norteavam as preocupações dos geógrafos durante o século passado: a primeira, representada por Ritter, era concebida como a "via histórica", ou seja, a observação da superfície terrestre era norteada pela idéia da história cultural. A segunda, a mais antiga e que as vezes se confundia com a primeira, consistia na tentativa de dividir a superfície terrestre a partir de fronteiras naturais. Com a 
primeira concepção, segundo Fröbel em sua contribuição metodológica de 1831, desenvolveu-se um princípio totalmente novo que a pura Geografia (Erdkunde), na qualidade de ciência natural, não conhecia: a influência estética da natureza sobre os homens, a qual se expressa em manifestações exitantes, cuja observação não é perceptível externamente, e sim internamente. Daí depreende-se que uma descrição da relação de troca entre natureza/homem sempre contará com elementos objetivos e subjetivos, onde, no caso de uma, tratar-se-á de uma descrição científico-natural e, na de outra, de uma interpretação estética, a qual somente produzirá quadros (Gemälde) e nunca será propriamente científica. Concluindo, Fröbel afirmou que a Geografia (Erdkunde) só será científica quando compreendida como ciência natural (Fröbel, apud SCHULTZ, 1980:52).

Portanto, a principal crítica atribuída a Ritter era a de que ele analisava e comparava os espaços terrestres (Erdräume) a partir de aspectos estéticos, incorporando aspectos histórico-culturais dos lugares. Segundo a concepção dominante, para boa parte dos geógrafos da época, a Geografia só teria se afirmado quando a geologia, a mineralogia e a climatologia passaram a ter realce dentro dela.

Mas Ritter também teve seus mestres; dentre eles o principal foi Herder. Ratzel, em 1882, afirmou que Herder já tinha expressado claramente a idéia básica de Ritter: que a história não está ao lado, senão dentro da natureza. Exatamente as assim chamadas idéias teleológicas teriam pertencido originalmente muito mais a Herder do que a Ritter. Já em Mayr, numa de suas obras de 1880, lê-se que Herder mesmo fora aluno de Kant, quando este filósofo ainda estava vinculado ao círculo de Leibniz. É a ele que se remetem as idéias básicas de Herder e Ritter, concluiu o autor. Neste sentido também Plewe, em 1932, depois de estudar a relação entre Herder e Ritter, apontou Leibniz como o verdadeiro pai das concepções de Ritter (SCHULTZ, 1980: 54-55).

Entretanto, a tradição da "ciência de Ritter" transformou-se numa tradição de Geografia escolar. Quem quisesse dedicar-se à pesquisa, no sentido da tradição de ciência natural de Humboldt, associava-se a outros grupos, como geólogos ou pesquisadores viajantes.

Richtofen, em 1903, afirmou que Ritter não conseguiu formar uma escola de geógrafos que desse continuidade às suas ricas concepções. Aínda quando vivo, a Geografia descritiva já desandara novamente para uma simples compilação, transformando-se numa serviçal da História e da Estatística. Plewe, em 1932, complementou dizendo que de Ritter é preciso que se diga que ele sobreviveu a si mesmo, porque é um fato lamentável que suas elaborações, com raras exceções, tenham sido arrastadas adiante e desacreditadas por representantes insípidos, até que, por volta de 1870 , se pode falar da falência da escola de Ritter (SCHULTZ, 1980:55).

Já Peschel, em 1877, foi bem mais incisivo na sua crítica a Ritter, quando afirmou que a obra deste autor foi, acima de tudo, uma "teologia geográfica", na medida em que ele fazia crer que a formação e o ordenamento dos espaços terrestres resultariam de uma predestinação. Neste sentido, cada espaço individual representaria uma força moral, a qual como que se manifestaria nas suas criaturas. À geografia (Erdkunde) 
caberia reconhecer a finalidade dos fenômenos. Na realidade, Peschel se contrapôs apenas à concepção teológica presente na análise de Ritter, na medida em que não se contrapunha à sua compreensão de Geografia (SCHULTZ, 1980:69).

Esta fase da Geografia deve ser contextualizada, tendo em vista que vivia-se a época de pleno domínio do método positivista no campo científico. Esta filiação ao positivismo manifestava-se no princípio da unidade do método científico, qual seja, a idéia da existência de um único método comum a todas as ciências, as quais seriam, conseqüentemente, definidas por objetos próprios. Esta postura positivista introduz um acentuado ranço naturalista na Geografia, na medida em que descaracteriza as qualidades próprias dos fenômenos humanos e impele sua análise para a analogia com os procedimentos das ciências naturais.

Schlüter afirmou que nesta época a questão "se o homem realmente integra a Geografia", não era mais sequer discutida. Problemático tornou-se, entretanto, decidir quais aspectos relacionados ao homem e em que circunstâncias deveriam ser incluídos nos estudos de Geografia. E esta questão estava de novo intimamente relacionada à discussão da unidade da Geografia, continuou o autor, dizendo que "o problema da unidade da Geografia não será resolvido enquanto a Geografia dos homens não for introduzida no grande edifício da Geografia, enquanto não se encontrar amalgamada com a Geografia Física" (Schlütter, apud SCHULTZ, 1980:80).

No afã de definir o objeto de estudo da Geografia, aprofundou-se também a discussão entre "Erdkunde" (Geografia Sistemática ou Geral) e "Länderkunde" (Geografia Regional) entre os geógrafos alemães da época da virada do século.

Alfred Hettner, um dos expoentes desta discussão, manifestava-se claramente a favor da Länderkunde, com o intuito de transformar a Geografia num "complexo de ciências" (Complex von Wissenschaften), unificando-a. Assim Hettner propôs a volta a Ritter, abdicando, no entanto, da sua teleologia. Respondendo à sua própria pergunta "o que é a Geografia?", Hettner afirmou tratar-se de todo o histórico desenvolvimento em direção da Länderkunde, ou então, "da ciência dos diferentes espaços da superfície terrestre".

Hettner quer a interpretação desta resposta não só como descrição histórica mas também como prescrição, uma vez que a sua frase contém um significado tanto descritivo como normativo. Por um lado, enfatizou Hettner, o "Sistema da ciência" (System der Wissenschaft) não se deixa construir "a priori", é preciso descobrir como a ciência avança, antes de se prescrever como ela deve avançar. Por outro lado, ele requeria uma fundamentação e uma explicação para este desenvolvimento histórico. Em 1919, na sua obra intitulada "A unidade da Geografia na ciência e no ensino", ele afirmou que "nós devemos justificar a essência da Geografia, tal como ela se desenvolveu historicamente, perante o juízo da lógica, e explicá-la a partir do sistema lógico da ciência". Tal sistema lógico é, na realidade, atribuição da Filosofia, continuou Hettner, mas no caso da Geografia , ela falhou até agora. Tendo em conta, portanto a necessidade urgente de elaborar definições para a Geografia, ele mesmo propôs um "Sistema das Ciências" (System der Wissenschaften), concebido como "norma cientí- 
fica", que deveria conduzir a pesquisa e o ensino em Geografia para o caminho "correto". Não é de surpreender, segundo Schultz, que Hettner, neste caminho "lógico-sistemático" também tenha chegado ao conceito da Geografia Regional: "Ela - a Geografia - é a ciência da organização espacial dos fenômenos na superfície terrestre", afirmou ele em 1905. Assim Hettner pôde juntar facilmente a metodologia descritiva e normativa numa unidade:

Estas ciências crescem lentamente para dentro de um legítimo sistema lógico. (...) A classificação (isto é, o desenrolar da histórica divisão de tarefas na ciência) adapta-se à essência dos objetos, isto é, obtém cada vez mais legitimidade lógica (Hettner, apud SCHULTZ, 1980:83).

A continuidade histórica, à qual Hettner se refereria, é, contudo, discutível. É a Ritter que Hettner seguiu, instalando uma continuidade que se manifesta somente nos escritos populares e, em parte, na escola. E esta continuidade é tão pouco respeitável, afirmou Schultz, que o próprio Hettner a negou.

Mas onde se expressou então a unidade da Geografia na concepção de Hettner? "No método", respondeu ele mesmo em 1895. Mas por método ele não compreendia qualquer procedimento na busca do conhecimento, não o caminho para o objetivo, senão o objetivo, o próprio objeto da Geografia.

Mesmo que em Hettner a referência à observação corológica (chorologischer Betrachtungsweise), à visão corológica (chorologischem Gesichtspunkt), à interpretação corológica (chorologischer Auffassung) e ao ponto de vista corológico (chorologische Standpunkt) sejam uma constante, ele queria expressar mais do que um seletivo interesse de pesquisa. "Os objetivos do pesquisador já se expressam no objeto a ser pesquisado", eles são por assim dizer "a essência deste objeto", afirmou ele também em 1895. "A observação geográfica não pode ser outra, a não ser corológica". É da estrutura do objeto que ela é forjada, complementou o autor:

A tarefa da Geografia é observar o caráter diverso (a particularidade, a essência, a natureza) das diferentes áreas da superfície terrestre, os fenômenos concretos da superficie terrestre, (...) as partes da terra, países, paisagens e áreas, como tais (como unidades naturais e como individualidades), além de reconhecer como os diversos fenômenos conjuntamente influenciam o caráter de um país ou de uma área, como se expressam numa paisagem.

E, mais adiante, Hettner complementou dizendo que

o geógrafo, que não cultiva a Geografia Regional corre sempre o risco de perder o chão da Geografia. Quem não a compreende não é um autêntico geógrafo (Hettner, apud SCHULTZ, 1980:84-85). 
Mas as críticas à proposta de Hettner não tardaram. Leutenegger, em 1924, por exemplo, afirmou que a Geografia Geral, desta forma, teria se perdido. No entanto, o que ela ensina deve ser compreendido para que se possa entender obras de Geografia Regional bem elaboradas, e mais ainda, para poder escrevê-las (Leutenegger, apud SCHULTZ, 1980:86).

Sem dúvida nenhuma foi Schlüter, dentre os geógrafos alemães da época, quem melhor reconheceu os limites das formulações de Hettner. Tomando ao pé da letra, ele não fez mais do que paralisar a pesquisa em Geografia, afirmou Schlüter em 1912.

Segundo Schlüter, existem somente duas ciências concretas: as históricas e as objetivo-sistemáticas (gegenständlich-systematischen). Em função disto ele rejeitou o terceiro grupo de Hettner, as ciências corológicas, afirmando que:

aquilo que nós momentaneamente enxergamos como um arranjo espacial de certos elementos, aparece, numa elaboração mais apurada como objeto, que desta forma se coloca novamente em relação com outros elementos espaciais (...) Assim, o antagonismo entre observação corológica e sistemática desaparece, uma vez que a observação espacial foi substituída pela observação objetivaconcreta (Schlïter, apud SCHULTZ, 1980:88).

Desta forma Schlüter define a unidade da Geografia, desde o princípio, como objetiva-concreta. A especificidade da Geografia não se expressa no fato dela fazer pesquisa numa aborgagem causal-genética, porque isto todas as outras ciências também fazem; ela se torna marcante muito mais em função daquilo que ela procura apreender. E isto se revela naquilo que ela descreve. A unidade do objeto da Geografia se expressa na contemplação: montanhas, rios, campos, matas, estradas, canais, jardins, assim como povoados e cidades são resumidos numa única forma pelos geógrafos: "o que é apreendido é o quadro da paisagem".

"Quem agarra muito, não consegue segurar", afirmou Schlüter em 1920. E continuou dizendo que uma Geografia que pretende estudar a influência da natureza sobre os homens amplia a esfera dos fenômenos ao infinito, na medida em que nenhuma manifestação humana está imune a esta influência. Delimitar a área de atuação da Geografia só seria possível se ela se concentrasse no que é perceptível, através do sentido das representações espaciais (Sinne der Raumvorstellungen), através da visão e do tato, ou seja, "a forma visível". Mais adiante ele afirma que a Geografia está toda moldada pela contemplação (ist ganz auf Anschauung gestellt). Mas carrega na sua essência a noção de que as coisas não podem ser tomadas simplesmente assim como se apresentam. Elas devem, antes de mais nada, tomar a forma das necessidades da Geografia (Schlüter, apud SCHULTZ, 1980:88).

Mas Schlüter, por sua vez, também foi criticado por Hettner, que afirmou que as diferenças entre ambos poderiam ser reduzidas a diferenças terminológicas. "Na realidade existe somente um antagonismo nas nossas visões", afirmou Hettner em 1907. "Eu quero introduzir o espiritual na Geografia, Schlüter quer excluí-lo. Ele não admite 
lugar em nossa ciência a nada que seja puramente espiritual. Mas quando se limita a Geografia desta forma, ela tem que, necessariamente secar e empobrecer." Mais adiante Hettner acusou Schlüter de estar se afastando arbitrariamente da histórica atribuição da Geografia, de destroçar a correlação causal dos fenômenos e de chocar-se contra a lógica das ciências (Hettner, apud SCHULTZ, 1980:90).

Schlüter, no entanto, não se sentiu atingido por estas críticas. Segundo Schultz ele não quis limitar a Geografia à percepção sensorial da paisagem (sinnlichen Eindruck der Landschaft), como afirmou Hettner, senão simplesmente retirar dentre os objetos de pesquisa da Geografia os não visíveis fenômenos espirituais, valorizando-os, entretanto, como fatores que dão forma aos objetos. A explicação de uma paisagem, afirmou Schlüter em 1899, tem que apreciar todos os tipos de causas, estejam eles na natureza da terra ou no espírito dos homens (Schlüter, apud SCHULTZ, 1980:90).

Segundo Schultz, Hettner via a si e a Schlüter como representantes de duas amplas tradições. Numa, onde ele também incluia Schlüter, a qual encontramos principalmente na pintura de paisagens, paisagem é o olhar sobre uma área, orientado, mas não necessariamente, pelo senso estético. Mesmo que Hettner desejasse fortalecer a Geografia estética (entendida como a percepção sensorial da superfície terrestre), a Geografia não deveria ser absorvida por ela. "Isto Schlüter também não quer, mas é a consequência lógica da sua visão", afirmou Hettner em 1907. A segunda tradição, que ele também atribuia a si, Hettner identificou como a tendência marcada pela tentativa de dividir a superfície terrestre em "áreas naturais". Nesta concepção, paisagem significava uma área delimitada por outras a partir de características naturais. Ambos apontavam a Geografia como "a ciência do ordenamento espacial dos fenômenos". Mas enquanto Schlüter traduzia "ordenamento espacial" como junção fisionômica, Hettner falava de uma unidade causal interna dos elementos. Objeto e fatores condicionantes são colocados lado a lado por Schlüter. Hettner, por outro lado, compreendia ambos como "unidade natural", à qual se podia atribuir especificidade ou individualidade, verdadeira individualidade, como ele mesmo ressaltou em 1919. Ele denominou estas porções de terra, como países, paisagens ou áreas. Elas se diferenciavam para ele somente pelo seu tamanho. Quando Schlüter falava de paisagem, ele se referia a uma unidade fisionômica, mais especificamente, àquilo que a observação, no primeiro olhar, apreende. Contrapondo-se, Hettner afirmou que a Geografia não pode nunca aceitar a compreensão da paisagem como um quadro, senão que tem que apreender toda a essência das áreas (Länder) na correlação de todos os fenômenos, na mesma medida, como se manifestam na paisagem (Hettner, apud SCHULTZ, 1980:91).

Em outro texto, no entanto, Schlüter veio ao encontro de Hettner quando afirmou que sempre se pode relacionar, de forma frutífera, os elementos da paisagem natural com os da paisagem cultural. Definitivamente fora de cogitação, entretanto, estava para ele a possibilidade de compreender, de forma meio poética, o "todo real como unidade", como o fizeram Estrabão, Herder, Ritter, Ratzel e muitos outros. Somente o primeiro olhar, o olhar na paisagem, permite compreender montanhas, rios, matas e 
moradias como unidade. Mas, assim que se tiver penetrado racionalmente nos aspectos vistos, deve-se desfazer o quadro unitário e levantar contraposições. Schlüter aconselhou a Geografia a manter-se na contraposição entre natureza e homem, e não numa unidade intrínseca da vida com o mundo inorgânico (Schlüter, apud SCHULTZ, 1980:91).

Depois da Primeira Guerra Mundial, e no decorrer da década de 20, passou a ser aceita também nas Universidades a concepção de que a Geografia não é uma ciência geral da Terra (allgemeine Erdwissenschaft), e sim uma abordagem regional (Länderkunde).

Importante, no entanto, é frisar, como o fez Heiderich em 1927, o que se entendia por Länderkunde nesta época: "Geografia é Länderkunde, mas Länderkunde não no sentido político de Geografia dos Estados e sim como Geografia das particularidades fisícas e culturais das paisagens da superfície terrestre" (Heiderich, apud SCHULTZ, 1980:123).

Com esta abordagem da Geografia Regional (Länderkunde) como Geografia das paisagens (Landschaftskunde) retomou-se a polêmica do período anterior à Primeira Guerra Mundial, entre Hettner e Schlüter, sobre a definição mais adequada de paisagem.

Para vários geógrafos da época, e dentre eles Friederichsen, no entanto, independente de uma resposta definitiva a esta pergunta, passaria a ser tarefa da Geografia elaborar uma Geografia geral das paisagens da Terra, no sentido de uma fisionomia da superfície terrestre (SCHULTZ, 1980:123).

Com a solução para o problema do objeto da Geografia resolver-se-ia também o problema da unidade da Geografia. "Com a especificidade do objeto, centrado na paisagem, o qual nenhuma outra ciência poderia disputar, encontra-se também a sua unidade, uma vez que na paisagem, a natureza e a obra dos homens estão intimamente entrelaçados" (Heiderich, apud SCHULTZ, 1980:124).

Waibel, sem sombra de dúvida, percorre a mesma trajetória dos geógrafos que se queriam fazer respeitar como cientistas na época: começa nas ciências naturais, estudando o mundo das plantas e dos animais, na tradição de Humboldt, para, num segundo momento, tomar consciência da importância do papel da História, e do homem consequentemente, na configuração das paisagens, na tradição de Ritter. Introduz o econômico nas suas análises (Wirtschaftsformation) e passa a analisar as paisagens como paisagens culturais, na tradição de Schlüter e Hettner.

\section{A Paisagem Cultural como categoria central na obra de Leo Waibel}

A primeira metade do século XX foi marcada por discussões importantes no campo da Geografia, especialmente no que diz respeito à concepção da paisagem, onde a ação da sociedade no espaço passa a ser contemplada enquanto objeto de pesquisa. Segundo Hönsch, observou-se um deslocamento da temática central da pesqui- 
sa em Geografia: de trabalhos analíticos, amparados nas ciências da natureza, passouse a incorporar a problemática sócio-econômica. E um avanço significativo no campo da Geografia Econômica passou a ser a incorporação de princípios e modelos sócioeconômicos, a partir da obra de autores como Von Thünen e Christaller. Questões sobre a dinâmica do desenvolvimento econômico e conseqüente busca de espaços mais adequados ao mesmo, passam a ter destaque. Esta crescente importância da Geografia Econômica estava relacionada à relativa estabilidade que o capitalismo apresentava na Alemanha da época. A exigência pelo uso racional do próprio espaço colocava a organização do espaço econômico na ordem do dia (HÖNSCH, 1971:26).

Neste contexto Waibel passou a orientar-se para análises sistemáticas no campo da Geografia Econômica, especialmente no que dizia respeito ao espaço agrário. Nas discussões referentes à Geografia da Paisagem (Landschaftskunde) Waibel deu a sua contribuição quando passou a destacar o papel dos homens na formação da paisagem cultural, conceito este que tem sua origem nas pesquisas sobre a paisagem do início do século XX, expressando a influência dos homens na formação e transformação da superfície terrestre.

Após a Primeira Guerra Mundial e ao longo da década de vinte criou-se um relativo consenso, também nas Universidades, de que a Geografia não era uma ciência geral da Terra, e sim uma ciência regional (Länderkunde). Mas nesta concepção regional, a Geografia não era entendida, no sentido político, como Geografia dos Estados (Länder) e sim como a Geografia da superfície terrestre dividida em paisagens, com suas características físicas e culturais. $\mathrm{Na}$ realidade, com esta compreensão da Geografia Regional (Länderkunde) como Geografia da paisagem (Landschaftskunde) recoloca-se a velha disputa entre Hettner e Schlüter, sobre a definição de paisagem (SCHULTZ, 1980:123).

Friederichsen não tinha dúvidas de que, do ponto de vista científico-metodológico, agrupar todas as considerações sobre o conceito de paisagem num único conceito central poderia se transformar num grande avanço para a Geografia (Friederichsen, apud SCHULTZ, 1980:123).

E é exatamente isto o que acontece, na medida em que a paisagem passava a ser entendida como única possibilidade da Geografia ter o seu objeto de pesquisa próprio, sem necessidade de disputá-lo com outras ciências.

Com esta solução para o problema do objeto da Geografia, solucionou-se também o problema da sua unidade. Com a definitiva aceitação da paisagem como objeto de pesquisa da Geografia ela também descobre a sua unidade, uma vez que na paisagem a natureza e a obra dos homens estão intimamente entrelaçadas (Heiderichsen, apud SCHULTZ, 1980:124).

Mas havia uma outra questão que passou a se colocar a partir desta época: a Geografia passaria a ser abordada como Landschaftskunde ou como Länderkunde, ou expressaria as duas ao mesmo tempo?

Segundo Gradmann, a controvérsia em torno do conceito de paisagem de Schlüter deixou de ser um problema. Sem muita reflexão unificava-se a terminologia de 
Hettner e de Schlüter e estabelecia-se que ao geógrafo (Länderkundler) cabia destacar os aspectos mais importantes da paisagem e os mais eficazes do ponto de vista geográfico (Gradmann, apud SCHULTZ, 1980:125).

Na realidade a resposta à questão colocada dependia, antes de mais nada, do nível de diferenciação que se pretendia estabelecer entre Landschaftskunde e Länderkunde. Segundo Schultz, a maioria dos geógrafos não relacionava diferenças de conteúdo ao utilizar um ou outro. Quem utilizava Länderkunde ao invés de Landschaftskunde (ou vice-versa), mudava o termo e a base de legitimação, o objeto e a preocupação central, entretanto, continuavam as mesmas (SCHULTZ, 1980:126).

Foi durante a sua estada em Bonn que Waibel passou a ocupar-se mais com a discussão em torno da concepção de paisagem. Na época Waibel ocupava-se com o aprofundamento do conceito de formação econômica, apoiando-se em Schlüter, e também no aprofundamento da concepção de paisagem cultural, conhecida desde Ritter e também usada por Hettner.

Segundo Waibel, a discussão em torno da paisagem se expressa de diferentes formas: fala-se de uma paisagem natural (Naturlandschaft), de uma paisagem cultural (Kulturlandschaft) e de uma paisagem econômica (Wirtschaftslandschaft). Passarge, por sua vez, tentou desenvolver uma disciplina geográfica específica denominada Landschaftskunde, enquanto Schlüter falava de uma Landschaftsgeographie.

Schlüter usava a expressão paisagem somente no sentido fisionômico, afirmou Waibel:

Para ele paisagem significava o concreto, o visivel, o sensivelmente perceptível na superficie terrestre. Todos os aspectos não perceptiveis pelos sentidos, principalmente os fenômenos espirituais, ele exclui da paisagem e com isso da geografia. (...) As assim chamadas coletividades (Gemeinschaften), como Estados e religiões ou nem pertencem à geografia ou só estão superficialmente relacionados a ela (WAIBEL: 1933:198).

E esta é a razão pela qual muitos geógrafos discordam da concepção de paisagem de Schlüter, complementou Waibel.

Waibel era da opinião de que aspectos sociais, religiosos e politicos não devem ser excluídos da geografia. No entanto, "mesmo que a análise de Schlüter não tenha conseguido abranger todas as atribuições da geografia, ela será sempre de grande importância metodológica para a mesma", afirmou.

Bem diferente foi a concepção de Passarge sobre paisagem, quando afirmou que "a Geografia da paisagem se constitui num novo ramo da geografia", escreveu o autor no ano de 1921. Em outra ocasião ele afirmou: "O que se vê é a paisagem" (PASSARGE, 1924). Mas nunca discutiu a relação de sua concepção de paisagem com a paisagem fisionômica de Schlüter, ou com a concepção de "paisagem natural". Um tanto mais claramente ele definiu em outra ocasião: "A paisagem é o palco dos animais e dos homens" (PASSARGE, 1924:217). Mas animais e homens não são tratados como 
objetos visíveis na paisagem de Passarge, como em Schlüter, senão somente na medida em que são dependentes da paisagem (no sentido de Passarge). Assim a paisagem de Passarge reconhece no relevo, clima, vegetação, tipos de solo um objeto, enquanto que em relação a animais e homens, somente uma relação de dependência" (WAIBEL, 1933:203).

Na concepção de Waibel, entretanto,

a paisagem, no sentido usual, é aquele recorte da superfície terrestre, e a correspondente abóbada celeste, que cabe no horizonte que podemos enxergar a partir de um determinado ponto. Nós sempre enxergamos a paisagem em perspectiva. "O homem não esclarecido enxerga-a ingenuamente, o artista percebea subjetivamente e tenta reproduzi-la num quadro, enquanto o geógrafo, como cientista, ambiciona descrevê-la objetivamente e compreendê-la na sua totalidade" (Schlüter). Junto a isto ele terá que, necessariamente, efetuar uma outra delimitação da paisagem. Objeto de observação geográfica, acima de tudo científica, não pode ser o recorte mais ou menos casual (...) da superficie terrestre que nós olhamos aproximadamente de um miradouro. A paisagem, no sentido científico, obviamente transpõe o nosso horizonte e abrange todas as áreas que possuem o mesmo caráter de paisagem.Também não podemos observá-la em perspectiva e sim numa projeção vertical, via de regra do alto, de um avião. "Ela é o Aufriß (alçado) para a base representada na carta" (Penck). Neste sentido a paisagem é um conceito fisionômico; ela estende-se aos fenômenos visiveis da superfície terrestre no sentido amplo, incluindo inclusive a atmosfera (WAIBEL, 1933:197).

Mas esta concepção de paisagem não é a única que a Geografia conhece, continuou Waibel.

Ao lado da paisagem fisionômica aparece a assim chamada "paisagem natural", um conceito que sempre de novo leva a grandes confusões e que, semelhante à expressão "fronteiras naturais", deveria ser abandonado. Uma paisagem natural é uma área caracterizada por particularidades naturais que a diferencia das áreas vizinhas (Hettner). A expressão natural significa aqui o não artificial que se estende a todas as particularidades de uma área, sejam elas visiveis ou não, inclusive às manifestações espirituais dos habitantes do lugar. Esta é a diferença básica da paisagem fisionômica. Por isso a Geografia inglesa também não fala em "paisagens naturais", senão em "regiões naturais" (Herbertson) (WAIBEL, 1933:198).

Ainda segundo Waibel, desde aproximadamente 1880 até a primeira guerra mundial o estudo das formas do relevo esteve em primeiro plano, o que desalojou cada 
vez mais a geografia dos homens de Carl Ritter. No entanto, ao contrário de muitos esforços recentes, afirmou Waibel, é preciso aceitar que o relevo é o fenômeno mais importante da superfície terrestre assim como a base para qualquer forma de vida. Além disso, o relevo é o elemento mais facilmente observável e isso faz com que na geomorfologia o "pensar e observar geográfico" sejam mais desenvolvidos. Esta disciplina, portanto, precisa de um lugar de destaque na geografia, ao mesmo tempo em que não pode ser tomada em prejuizo das outras disciplinas geográficas (WAIBEL, 1933:200).

Por isso nós hoje também falamos da paisagem natural, continua Waibel, pela qual entendemos a manifestação dos fenômenos da natureza e a colocamos lado a lado com a paisagem cultural, que só abrange o que resulta da ação dos homens. Uma tal paisagem natural é, por exemplo, uma floresta desabitada ou um deserto. Num sentido um pouco mais amplo, alguns geógrafos também falam de paisagem natural quando os fenômenos da natureza são fisionomicamente mais expressivos do que a transformação feita pela ação do homem. Uma floresta com pequenas áreas desmatadas ainda seria uma paisagem natural. No entanto, se a floresta estiver toda desmatada, e em seu lugar aparecerem campos e colônias, então podemos falar de uma paisagem cultural (WAIBEL, 1933:2000).

Waibel, portanto, entendia a paisagem cultural, dentro da geografia agrária, como resultante do uso predominante do solo, ou seja, do tipo, de cultivos, técnicas utilizadas, estradas e instalações, determinado pela formação econômica.

Há também aquelas paisagens naturais, como por exemplo o pampa argentino (Schmieder) ou a savana africana (Pierre la Bathie) que já foram completamente transformados pelo uso que o homem faz das mesmas. Isto coloca novos problemas para a Geografia. É necessário investigar o grau de influência e transformação que as assim chamadas paisagens naturais sofreram com a ação do homem (WAIBEL, 1930:201).

Desta maneira, a pesquisa da paisagem cultural de Schlütter se salientou dentre os interesses geográficos:

Nós partimos do quadro fisionômico das particularidades dos elementos da paisagem, sejam povoados, caminhos ou espaços usados economicamente, observamos e descrevemos a forma e a aparência procurando esclarecê-los através da sua função e do seu desenvolvimento. O método é exatamente o mesmo que o da paisagem natural, o que leva Schlülter a falar de uma "morfologia da paisagem cultural", porque os objetos, tanto da paisagem natural quanto da paisagem cultural, são materializados e se colocam como elementos visíveis da pai- 
sagem para nós. A Geografia dos homens torna-se assim, de certa forma, objeto das ciências naturais (WAIBEL, 1933:201).

Neste sentido, afirmou Waibel, não existe uma única concepção de Landschaftskunde. Três concepções se colocam: a Geografia habitual (übliche Geographie) examina a paisagem em todas as suas particularidades, sejam elas visíveis ou não; uma paisagem equivale para ela, de maneira geral, à menor unidade espacial (ein Land kleinste ordnung). Schlüter atenta somente para os fenômenos perceptíveis na paisagem e neles quer delimitar o objeto da Geografia. Passarge, por sua vez, coloca clima e vegetação em destaque e analisa os fenômenos deles dependentes de maneira comparativa e tipológica (WAIBEL, 1933:204).

Waibel, no entanto, discorda de Passarge na medida em que não era adepto do determinismo geográfico. Afirmava que o grau de aproveitamento pelos homens das possibilidades que a natureza oferece depende de fatores econômicos e culturais (WAIBEL, 1929:426).

Neste sentido, a importante discussão e análise da obra de Waibel, feita por Ingrid Hönsch, intitulada "Leo Waibel: eine kritische Würdigung unter besonderer Berücksichtigung seines Beitrages zur Entwicklung agrargeographischer Lehrmeinungen und Arbeitsmethoden" (Leo Waibel: uma análise crítica com ênfase na sua contribuição para o desenvolvimento de teorias e métodos em Geografia Agrária), tese de doutorado apresentada na Universidade de Potsdam em 1971, aponta questões pertinentes ao tema. Segundo a autora, foi dentro do movimento por uma geografia única, no início do século atual, que o significado de paisagem ganhou sentido novamente, depois de ter sido reprimido durante o período de domínio do "princípio da causalidade".

Com a fragmentação da Geografia inaugurou-se uma especialização cada vez maior, ou seja, a Geografia despedaçou-se em várias disciplinas autônomas. Hettner tentou aproximar o social e o natural numa Geografia única (Länderkunde). Segundo este, a observação conjunta da natureza e dos homens na Geografia não é "dualista", como ocorre em outras ciências da Terra. A apreensão geográfica ou corológica da natureza e dos homens é una em todos os aspectos essenciais e não conduz de maneira nenhuma a duas partes diferenciadas na Geografia.

Que na Geografia deve-se dar atenção à natureza e aos homens na mesma medida só é colocado em dúvida por pessoas de fora da Geografia, que nunca se ocuparam com questões de Geografia ou se ocuparam apenas com uma parte dela, afirmou Hettner em 1927 (HETTNER, 1927:126).

Portanto, continuou o autor, a unidade da Geografia no sentido de uma ciência corológica ou geográfica (Länderkundliche Wissenschaft) não pode ser apreendida com uma simples apreciação estética da paisagem, senão a partir da essência dos espaços (Länder), das paisagens e das localidades. Nenhum fenômeno da superfície terrestre pode ser analisado de forma isolada; somente na comparação deste fenômeno com fenômenos da mesma ordem em outros lugares ele se tornará compreensível (HETTNER, 1927:9). 
Hettner, portanto, enfatizou a perspectiva corológica na geografia, que os geógrafos alemães denominaram Länderkunde e que tem como objetivo a descrição da topografia dos países ou Estados, com ênfase nos dados estatísticos e na descrição de lugares.

Esta perspectiva desembocou, entre os franceses com Vidal de La Blache, na Geografia Regional.

Assim, Hettner pretendia, com a pergunta sobre a essência dos espaços (Länder) dar uma atribuição clara e específica à Geografia. A consequiente delimitação do espaço de pesquisa, o princípio regional, passou a ser o ponto de partida da pesquisa. Na metodologia, contudo, a Geografia (Länderkunde) estagnou na causalidade.

Conforme Hönsch, esta perspectiva tentou desvendar relações entre alguns objetos geográficos que exprimiam tanto os fatores específicos do meio geográfico como a influência antrópica, sem analisar com exatidão os fenômenos em si (HÖNSCH, 1971:22).

Hettner entendia a Geografia não como um objeto, mas como um espaço - $e$ uma ciência de relação. O muitas vezes criticado "esquema geográfico" deveria servir como auxílio didático, além de clarear os aspectos mais importantes sobre os países em cuja base Hettner queria chegar a um "conseqüente parcelamento regional do todo" (PLEWE, 1959:25) e a uma investigação sobre as relações dos elementos nos espaços parcelados (HÖNSCH, 1971:23).

Continuando, Hönsch afirmou que:

A corrente da antropogeografia funcional na Geografia, assinalada por Overbeck (...), representado por Hettner e seus alunos, tinha a sua raiz filosófica no historicismo burguês. Hettner reconhecia o significado dos acontecimentos históricos para o desenvolvimento social dos países. Todavia, ele não os encarava como acontecimentos objetivos no correr da história como Marx e Engels, senão como subjetivos e individuais. Com isto Hettner tornou-se o representante das exigências da burguesia (HÖNSCH, 1971:23).

Já a Geografia da paisagem, representada por Schlüter, partiu do princípio fisionômico. $\mathrm{O}$ objeto dos trabalhos geográficos deveria ser a análise de recortes regionais da superfície terrestre, no sentido da totalidade:

Enquanto Ratzel representava a tese da força da paisagem como forjadora dos homens, Schlüter acentuava a força dos homens como forjadores da paisagem. A separação dos homens da natureza e a sua transformação em paisagem cultural foi colocada por Schlüter como o ponto central em suas elaborações. Estes princípios tiveram grande importância no conseqüente desenvolvimento da Antropogeografia e da Geografia Econômica. A aplicação da pesquisa da pai- 
sagem cultural genética na geografia da colonização trouxe novos conhecimentos que não perderam nada em atualidade até hoje (HÖNSCH, 1971:24).

Segundo Hönsch, na sua explanação sobre a Geografia da paisagem, Waibel chegou até à fronteira da concepção de Schlüter. A investigação da morfologia, da fisiologia e da constituição histórica da paisagem cultural desconsiderou, no entanto, as significativas correlações com a Economia. A aceitação, tanto do objeto de pesquisa, a paisagem, quanto da metodologia de trabalho e da terminologia da Geografia Física levaram a concluir que "a geografia dos homens, desta forma, manteve-se de certo modo como um objeto das ciências naturais".

Concluindo, Hönsch afirmou que de Hettner, Waibel teve a larga fundamentação na formação e a sua visão científica multifacetária. Também nas questões relativas à unidade da Geografia ele foi influenciado por Hettner. De Schlüter ele aceitou o princípio fisionômico na investigação de países e espaços econômicos. No entanto, é preciso salientar que nenhuma destas concepções foi usada de forma acrítica por Waibel (HÖNSCH, 1971:24).

Revisitar obras de autores clássicos da Geografia como Leo Waibel, portanto, adquire um novo sentido quando se tem a clareza de que para compreendê-las é necessário ir às origens do pensamento geográfico, através do resgate de textos que nunca se tornam "desatualizados".

\section{A PAISAGEM AGRÁRIA NA OBRA DE LEO WAIBEL}

Resumo: Este artigo trata da concepção de paisagem presente na obra de Leo Waibel, geógrafo alemão que trabalhou no Brasil no período de 1946 a 1950. Realça também a importância da releitura dos clássicos da Geografia alemã como forma de viabilizar a compreensão dos conceitos básicos da Geografia.

Palavras-chave: Paisagem, história do pensamento geográfico, superfície terrestre.

\section{THE AGRARIAN LANDSCAPE IN LEO WAIBEL'S WORK}

Summary: This article aims to explain the conception of landscape, present in Leo Waibel's works, a German geographer who worked in Brazil during the period from 1946 to 1950. It also enhances the importance of rereading the classics of German geography, as a way to turn feasible the comprehension of the most important geographic concepts.

Keywords: Landscape, history of geographic thought, earth surface.

\section{BIBLIOGRAFIA}

ETGES, Virgínia Elisabeta (2000a): Geografia Agrária - a contribuição de Leo Waibel. Santa Cruz do Sul: Edunisc. 226p. 
(2000b): Länderkunde und Erdkunde: a região no contexto geográfico. In: HELFER, Inácio. Pensadores alemães dos séculos XIX e XX. Santa Cruz do Sul: Edunisc. 210p.

FIGUEIRÓ, Adriano S. (1986): Evolução do conceito de paisagem: uma breve revisão. Revista Geosul, Florianópolis: Editora da UFSC. v.1, n.1.

HETTNER, Alfred (1927): Die Geographie, ihre Geschichte, ihr Wesen und ihre Methoden. Breslau: Ferdinand Hirt.

HÖNSCH, Ingrid (1971): Leo Waibel: eine kritische Würdigung unter besonderer Berücksichtigung seines Beitrages zur Entwicklung agrargeographischer Lehrmeinungen und Arbeitsmethoden. Pädagogischen Hochschule "Karl Liebknecht". Potsdam.

PASSARGE, S. (1924): Vergleichende Landschaftskunde. Berlin. H.4. S.V. (1921): Die Landschaft. Erdkundliches Wanderbuch. S.217.

SCHMITHÜSEN, Josef (1970): Geschichte der Geographische Wissenschaft. Bibliographisches Institut Mannheim/Wien/Zürich..

SCHULTZ, Hans Dietrich (1980). Die Deutsche Geographie von 1800 bis 1970. Ein Beitrag zur Geschichte ihrer Methodologie. Berlin: Selbstverlag des Geographischen Instituts der Freien Universität Berlin.

WAIBEL, Leo (1933): Was verstehen wir unter Landschaftskunde? Gotha. Geographischen Anzeiger, n.34.

(1929): Die Wirtschaftsgeographische Gliederung Mexikos. Geographische Zeitschrift. 